BULLETIN Bulletin hispanique

HISPANIQUE Université Michel de Montaigne Bordeaux

110-1 | 2008

Varia

\title{
Novelas a la venta en librerías españolas del Siglo de Oro (1600-1650)
}

José María Díez Borque

\section{OpenEdition}

1 Journals

Edición electrónica

URL: https://journals.openedition.org/bulletinhispanique/486

DOI: 10.4000/bulletinhispanique.486

ISSN: $1775-3821$

Editor

Presses universitaires de Bordeaux

Edición impresa

Fecha de publicación: 1 junio 2008

Paginación: 91-109

ISBN: 978-2-86781-511-9

ISSN: 0007-4640

Referencia electrónica

José María Díez Borque, «Novelas a la venta en librerías españolas del Siglo de Oro (1600-1650)», Bulletin hispanique [En línea], 110-1 | 2008, Publicado el 06 febrero 2012, consultado el 18 septiembre 2021. URL: http://journals.openedition.org/bulletinhispanique/486 ; DOI: https://doi.org/10.4000/ bulletinhispanique.486 


\title{
Novelas a la venta en librerías españolas del Siglo de Oro (1600-1650)
}

\author{
José María DíEz BorQue \\ Universidad Complutense. Madrid
}

L'étude se fonde sur les inventaires des librairies les plus importantes de certaines villes espagnoles, de 1600 à 1650. Il sagit de voir quels romans on y vendait et la portée de ces ventes, du point de vue de la culture littéraire. Les questions les plus importantes tournent autour de la proportion des romans dans l'ensemble des livres présents dans les librairies, le nombre d'exemplaires, la permanence des titres tout au long de la période étudiée, l'évolution du goût littéraire et, d'une façon plus significative, les différences décelées entre la mémoire littéraire, le canon des histoires littéraires et la réalité des ventes, pendant cette période.

Se toman en consideración los inventarios de librerias pertinentes, de varias ciudades españolas, en el periodo de 1600-1650, para estudiar las novelas que habia a la venta y lo que ello significa para la historia de la cultura y de la literatura. Cuestiones básicas son la proporción de novelas en el conjunto del fondo de las librerias y el número de ejemplares; la permanencia de títulos a lo largo del periodo estudiado; evolución del gusto literario y, muy significativamente, las diferencias entre la memoria literaria, el canon de las historias de la literatura y la realidad de las novelas a la venta en las librerías del Siglo de Oro.

This study considers stocks in the biggest bookstores of some relevant Spanish cities from 1600 to 1650. Which novels were sold? What influence did those sales have in terms of literary culture? Our main points of focus are the proportion of novels within the stocks, the number of copies, the permanence of titles during the period studied, the evolution of literary tastes and, more significantly, the differences between literary memory, literary canon and the actual sales during that period.

$B H i$, Tome 110, n $^{\circ} 1$ - juin 2008 - p. 91 à 109. 
Mots-clés: Siècle d'Or - Romans - Inventaires de librairies - Ventes - Réception Canon littéraire.

\section{INTRODUCCIÓN}

$\mathrm{M}$

E GUSTARÍA que pudiera haber respuestas más contundentes y certeras a preguntas tan incitantes como ¿qué novelas había a la venta en las librerías españolas del Siglo de Oro?, ¿quiénes eran los compradores?, ¿cuáles los índices de lectura?, ¿qué suponían, en proporción real, con respecto al resto de libros a la venta?, ¿cuáles eran las fases de apogeo y decadencia?, ¿cuál el ascenso y ocaso de los distintos géneros novelísticos? Pero como en tantos otros casos las fuentes de información con sus peculiaridades acotan alcances y marcan unas delimitaciones.

He tomado en consideración todos los inventarios de librerías pertinentes para el periodo 1600-1650 -referidos a varios tipos y ciudades espańolasteniendo en cuenta las relaciones que ofrecen Chevalier, Laspéras, Dadson, Delgado, Infantes - López - Botrel, además de estudios particulares como los de Prieto, Velasco, Cayuela ${ }^{1}$, etc. Pero el problema comienza en los propios inventarios, que no están elaborados con el detalle y rigor que hoy hubiéramos exigido. Así la forma de citar los títulos hace difícil identificar algunas obras (me he servido en esto, como se verá, de la fuente utilizada en cada caso) o puede llevar a confusión. En ocasiones se mezclan en los registros resmas de papel en blanco, resmas, manos y cuerpos,

1. Maxime Chevalier, «Inventarios de bibliotecas particulares», «Problemas generales y cuestiones de método", Lectura y lectores en la España de los siglos XVI y XVII, Madrid, Turner, 1976, p. 31-36; Jean-Michel Laspéras, «Chronique du livre espagnol. Inventaire de bibliothèques et documents de librairie dans le monde hispanique aux $\mathrm{XV}^{\mathrm{e}}, \mathrm{XVI}^{\mathrm{e}}$ et XVII ${ }^{e}$ siècles», Revue Française d'Histoire du livre, XXVIII (1980), p. 535-557; Trevor J. Dadson, "Apéndice 2. Lista de inventarios de bibliotecas particulares", Libros, lectores y lecturas, Madrid, Arco/ Libros, 1998, p. 516-529; Víctor Infantes, François Lopez, Jean-François Botrel, "Bibliografía: primera parte», Historia de la edición y de la lectura en España 1472-1914, Madrid, Fundación G. Sánchez Ruipérez, 2003, p. 787-820; y en esta misma obra Juan Delgado, "Los catálogos de libreros y editores», p. 133-141. José Manuel Prieto, Lectura y lectores (...), Mérida, Junta de Extremadura, 2004; Esperanza Velasco, Impresores y libreros en Zaragoza 1600-1650, Zaragoza, "Institución Fernando el Católico», 1998; Anne Cayuela, Alonso Pérez de Montalbán. Un librero en el Madrid de los Austrias, Madrid, Calambur, 2005; Anastasio Rojo, Impresores, libreros y papeleros en Medina del Campo y Valladolid en el siglo XVII, Valladolid, Consejería de Cultura, 1994.

En estos hay referenciados otros inventarios no pertinentes aquí. 
pliegos, objetos. Algunas veces, bajo el mismo registro se incluyen diversos títulos. En unas pocas ocasiones no se dan títulos, sino número de libros, sin especificar. Por otra parte, no todos los inventarios tienen el mismo carácter, pues si la mayor parte son, realmente, inventarios de librerías, algunos, como se verá, se refieren a los libros que se llevan a América o se limitan a compras particulares o a determinado precio de los libros. Para complicar las cosas en un mismo inventario puede aparecer el mismo título repetido en distintos registros. Aunque no sea equivalente, pues, registro y título, considero los datos porque son útiles para evaluar proporciones ${ }^{2}$.

No dejaré de decir que la continuada necesidad de operaciones aritméticas ha podido llevar a algún error que suplirá el lector bien intencionado. No se me oculta el enojo que puede producir la acumulación de datos, pero me parece imprescindible para asentar sobre terrenos sólidos el acercamiento al tema.

Así son las cosas y éstos los mimbres con que fabricar el cesto. Con todo, la intención de lo que sigue es dar respuesta -a la altura de las circunstanciasa algunas, y otras, de las preguntas formuladas al comienzo. No cabe dar a los datos ofrecidos la exactitud matemática que me hubiera gustado, pero sí tienen, creo, el suficiente valor orientativo para informar, aunque sea parcialmente, de la presencia de la novela en las librerías españolas del Siglo de Oro, la relación con otros libros a la venta, los títulos de éxito, el auge y declive de los géneros...etc. Cuestiones todas importantes para acercarnos a la «realidad de verdad», como decía Torres Navarro, fundamental para la historia de la literatura. Hay que esforzarse por conocer lo que ocurría en el

2. Sobre los problemas de inventarios de librerías vid. Juan Delgado, «Los catálogos de libreros y editores», cit.; vid. alguno de los estudios que cito en nota siguiente, y de las bibliotecas particulares, entre otros, Trevor J. Dadson, op. cit.; Víctor Infantes, «Las ausencias en los inventarios de libros y de bibliotecas", B.Hi, 99, 1 (1997), p. 281-292; Maxime Chevalier, “Lecturas y lectores...” veinte ańos después”", B.Hi., 99,1 (1997), p. 19-24.

Sobre las características del inventario, función y problemas metodológicos puede verse también: Víctor Infantes "La memoria de la biblioteca: el inventario», El escrito en el Siglo de Oro. Prácticas y representaciones. El libro antiguo español V. Dir. P. M. Cátedra, A. Redondo, M. L. López-Vidriero, ed. J. Guijarro, Salamanca, Universidad, Sorbonne, SEHL, 1998, p. 163-170. Son útiles además varios estudios: M. J. Pedraza, «Los estudios sobre inventarios y catálogos de bibliotecas en Aragón en la Edad Moderna», B.Hi, 99,1 (1997), p. 231-242; "Lector, lecturas, bibliotecas...: El inventario como fuente para su investigación histórica», Anales de Documentación, 2 (1999), p. 137-158; Bartolomé Bennassar, «Los inventarios postmortem y la historia de las mentalidades", La documentación notarial y la historia: Actas del II Coloquio de Metodología Histórica Aplicada, Santiago, Colegios Notariales, Universidad, 1984, p. 139-146, y varios de los estudios que cito en mis trabajos en prensa (nota 5). 
siglo para tener elementos de referencia histórica y contraste con lo que la memoria literaria ha retenido, con el canon ideal de excelencia de nuestros días o, incluso, con el papel y valor concedidos a la literatura. Éstos son los alcances de lo que me propongo aquí, y no entro en aspectos concretos de la actividad de impresores y libreros, comercio del libro, controles, catálogos, pleitos, libreros en particular, que cuentan con una bibliografía pertinente $^{3}$.

Pasemos ya a las fuentes de información y lo que aportan, es decir, a los distintos inventarios, señalando el número de registros y volúmenes en general y el de novelas en particular (en varias ocasiones he debido calcularlo por lo que hay que admitir un margen de error), para dar, a continuación, la relación de títulos de novelas y el correspondiente número de registros y ejemplares. Por el sentido de este estudio doy en forma abreviada los títulos, indicando el autor, para lo que me sirvo de la fuente utilizada en cada caso, aunque utilizo también las bibliografías y manuales pertinentes de literatura española ${ }^{4}$. Indico las obras que no tomo en consideración por no haber podido identificarlas, o caer fuera del marco literario acotado, y prescindo de las muy aisladas traducciones o novelas extranjeras. No indico la edición, por no especificarla el inventario, lo que impide saber cuál era la que estaba en la correspondiente librería.

Utilizo, como se ve, el término novela, sin entrar aquí en disquisiciones de teoría e historia de la literatura. Sirve para entendernos, y lo prefiero en este caso al de prosa de ficción, aunque, naturalmente, conozco los problemas que ello conlleva y las cuestiones que plantea, de las que, como digo, no me ocupo aquí.

3. Hay ya una extensa bibliografía sobre el tema en la que no puedo detenerme en particular. Aparte de los estudios citados de Cayuela, Dadson, Delgado, Laspéras, Velasco..., sirva de orientación: sobre librerías madrileñas (Agulló, Amat, Cayuela, Entrambaguas, López, Maldonado, Moll, Pérez Pastor, Marques de Saltillo, Simón, Vindel...) ; otras ciudades (Bécares, Gonzáles-Maillard...). Sobre gremios y hermandades (Paredes, Redondo...). Memoriales, pleitos, defensa del libro (Blecua, Moll, Sierra...). Mercado, catálogos (Cruickshank, Rodríguez Moñino, Wacquet-Bots, Whinnom...). Interesantes colectivos como los dirigidos por Cátedra, López-Vidriero y editado por Andrés, etc.

4. Además de los manuales y bibliografías al uso, para los libros de caballerías me ha sido especialmente útil Daniel Eisenberg-Ma Carmen Marín Pina, Bibliografía de los libros de caballerías castellanos, Zaragoza, Prensas universitarias, 2000. 


\section{FUENTES DE INFORMACIÓN Y CONTENIDO}

(Los inventarios no indican partes en los libros de caballerías lo que dificulta la identificación, autoría y correspondencias)

1) 1601: «Librería de Francisco Escalante», en A. Rojo Vega, Impresores, libreros y papeleros en Medina del Campo y Valladolid, Salamanca, Junta de Castilla y León, 1994, pp. 240-242.

- «Nos hemos decidido a copiar de ellos únicamente los libros baratos (...) cuyo precio estuvo por debajo de dos reales» (Rojo, p. 240)

- Número de registros: 10

- Número de volúmenes: 11

- No aparece novela.

2) 1601: «Registro Martín Sánchez de Solís pasajero que va en esta flota que se apresta para los reinos de Tierra Firme», en Irving A. Leonard, Romances of chivalry in the Spanish Indies (...) Berkeley, University of California, 1933, pp. 76-113.

- Número de registros: 81 cajas. C. 1100 registros. Se repite, en ocasiones, el mismo título en varios registros.

- Número de volúmenes: «In January 1601 there is a register of one deal, covering a total of some 10000 books» (Leonard, p. 14)

- $\quad$ Número de registros de novela: 84

- Número de volúmenes de novela: 524

- Relación de títulos, número de registros y número de ejemplares:

- Amadis de Gaula: ( ) 4/9

- Amadis de Grecia: (Feliciano de Silva) 8/19

- Arcadia: (Lope de Vega) 20/94

- Belianis: (¿Jerónimo Fernández. Pedro Guiral?) 1/1

- Clara Diana: (Bartolomé Ponce) 3/7

- Diana a lo divino: ( ) 2/8

- Espejo de Caballeros: (¿D.Ortúnez, P. de la Sierra, M. Martínez?, no especifica parte) $2 / 2$

- Florisel de Niquea: (Feliciano de Silva) 13/138

- Galateo español: (Lucas Gracián Dantisco) 4/30

- Guerras de Granada: (Ginés Pérez de Hita) 2/7

- ¿Guzmán de Alfarache?: (Mateo alemán) Libros de Pícaros 4/99

- Lazarillo de Tormes: (Anónimo) 4/9

- Lisuarte: (¿F. De Silva, J. Díaz?) 1/1

- Pastor de Fílida: (Luis Gálvez de Montalvo) 2/3 
- Pícaros: (?) 1/15

- Primaleón: (¿Francisco Vázquez?) 12/80

- Sergas de Espladián: (Garci Rodríguez de Montalvo) 1/2

No tomo en consideración: Entretenimiento de damas y galanes (2); Momo (15); El tahúr andaluz (6).

3) 1605: «Registro Diego Correa para dar y entregar en la Ciudad de Cartagena», en Irving A. Leonard, op. cit, pp.114-115.

- $\quad$ Número de registros: 21

- Número de volúmenes: 185

- $\quad$ Número de registros de novela: 3

- $\quad$ Número de volúmenes de novela: 98

- $\quad$ Relación de títulos, número de registros y número de ejemplares:-

- Quijote: (Miguel de Cervantes) 2/90

- Peregrino en su patria: (Lope de Vega) 1/8

No cuento El tahúr andaluz (6).

4) 1605: Librería de Jusepe Domenego. Murcia, en Lope de Pascual, «Libros y libreros en Murcia según los protocolos del siglo XVII», El libro antiguo español, II, ed. Ma Luisa López Vidriero y Pedro M. Cátedra, Universidad de Salamanca, BNM, SEHL, 1992, pp. 166-168.

- No dan el inventario completo.

«Pero ni [en] esta librería, como hemos dicho en la de Dorado, encontramos libros de caballería. Ni siquiera encontramos otros libros de lectura menor, que podríamos llamar: comedias, novelas, versos» (Pascual, p. 168).

5) 1606: «El fondo de la librería de Cristóbal López», Madrid, en Trevor J. Dadson, Libros, lectores y lecturas, Madrid, Arco Libros, 1998, pp. 467502.

- $\quad$ Número de registros: 387, hay algunos de resmas, papel blanco... Vid. apartado siguiente.

- $\quad$ Número de volúmenes: «El recuento de los fondos de la librería proporciona las siguientes cifras : 5841 libros (con 260 títulos distintos) y 12575 pliegos sueltos (formados por coplas, poderes, cartas de renunciación, palabras de consagración, pronósticos y lo que llaman "menudencias")» (Dadson, p. 291).

- $\quad$ Número de registros de novela: 33

- $\quad$ Número de volúmenes de novela: 239

- Relación de títulos, número de registros y número de ejemplares:

- Amadis de Grecia: (Feliciano de Silva) 2/2 
- Arcadia: (Lope de Vega) 2/139

- Belianis: (Jerónimo Fernández) 3/3

- Febo: (Diego Ortúñez) 2/2

- Celestina: (Fernando de Rojas) 1/4

- Cristalián: (Beatriz Bernal) 1/1

- Diana: (Jorge de Montemayor) 1/2

- Espejo de Caballerías: (Pedro de Reinosa) 1/1

- Florisel de Niquea: (Feliciano de Silva) 2/2

- Galateo y Lazarillo castigado: (Lucas Gracián Dantisco) 3/18

- Guzmán de Alfarache, 2a parte: (Mateo alemán) 1/1

- Lazarillo de Tormes: (Anónimo) 1/12

- Ninfas y pastores del Henares: (Bernardo González) 1/1

- Palmerín de Olivia: (¿Francisco Vázquez?) 1/1

- Pastor de Fílida: (Luis Gálvez de Montalvo) 1/2

- Peregrino en su patria: (Lope de Vega) 2/5

- Policisne de Boecia: (Juan de Silva) 1/2

- Primaleón: (¿Francisco Vázquez?) 2/2

- Quijote: (Miguel de Cervantes) 2/35

- Reinaldos: $1 / 1$

- Rogel de Grecia: (Feliciano de silva) 1/1

- Selva de Aventuras: (Jerónimo de Contreras) 2/2

No tomo en consideración: Una toledana discreta (E. Martínez)(1); Asno de Oro (L. Apuleyo) (2); Historias de Momo (2); Peregrino indiano (A. De Saavedra) (2); Historias trágicas (M. Bandello) (3).

6) 1607: Mariana Hernández, esposa del librero Pedro de la Torre. Madrid, en Cristóbal Pérez Pastor, "Impresores y libreros de Madrid, documentos referentes a ellos», Memorias de la Real Academia Española, XIII (1926), p. 325.

- Número de registros: 10

- Número de volúmenes: No da.

- Número de registros de novela: 2

- Número de volúmenes de novela: 16

- $\quad$ Relación de títulos, número de registros y número de ejemplares:

- Arcadia: (Lope de Vega) 1/6

- Celestina: (Fernando de Rojas) 1/10

7) 1608. Francisco López, Madrid, en Cristóbal Pérez Pastor, op. cit, p. 328; Christian Peligry, «Un libraire madrilène du Siècle d'Or. Francisco López 
le jeune (1545-1608)», Mélanges de la Casa de Velázquez, 12 (1976), pp. 219-250.

- No dan inventario completo.

- Número de registros: no dan

- $\quad$ Número de volúmenes: «plus de 15000 volumes (Peligry, p. 245)

- Número de registros de novela: no dan

- Número de volúmenes de novela: sólo citan 107

- $\quad$ Relación de títulos, número de registros y número de ejemplares:

- Arcadia: (Lope de Vega) 1/105

- Guerras de Granada: (Ginés Pérez de Hita) 1

- Guzmán de Alfarache, 2a parte: (Mateo Alemán) 1

8) 1610: Compra por Felipe Bonilla a Sebastián de Cormellas. Zaragoza, en Esperanza Velasco, Impresores y libreros en Zaragoza 1600-1650, Zaragoza, IFC, 1998, p. 260.

- No da inventario de la compra de más de 6000 libros (Velasco, p. 260). Entre las novelas menciona Fernando de Rojas, Celestina, 3; Miguel de Cervantes, Quijote, 6; López de Úbeda, Pícara Justina, 2.

9) 1610: Librería de Sebastián de Robles. Madrid, en Christian Peligry, «El inventario de Sebastián de Robles, librero madrileño del siglo XVII», Cuadernos Bibliográficos, 32 (1975), pp. 181-188.

- Número de registros: 99 (uno de manos de cartillas y otro de resmas de papel)

- Número de volúmenes: «encontraron en la tienda del difunto 1639 volúmenes» (Peligry, p. 182)

- $\quad$ Número de registros de novela: 2

- $\quad$ Número de volúmenes de novela: 10

- $\quad$ Relación de títulos, número de registros y número de ejemplares:

- Arcadia: (Lope de Vega) 1/9

- Pastor de Fúlida: (Luis Gálvez de Montalvo) 1/1

No tomo en consideración Nochebuena (3); La discreta toledana (1)

10) 1614 «Velázquez (Mateo), librero, encuadernador», en El Marqués de Saltillo, «Bibliotecas, libreros e impresores madrileños del siglo XVII», RABM, LIV (1948), pp. 284-285.

- Número de registros: 12 (más nueve de objetos de encuadernar)

- Número de volúmenes: 134

- No aparece novela 
11) 1615 Juan Dorado. Murcia, en Lope de Pascual, op. cit, pp. 164-166

- Número de registros: 98

- Número de volúmenes: «El total de los cuerpos de libros que había en la tienda se remonta a unos mil ciento sesenta y uno, poco más o menos» (Lope de Pascual, p. 165)

- $\quad$ Número de registros de novela: 2

- Número de volúmenes de novela: 10

- Relación de títulos, número de registros y número de ejemplares:

- Novelas: (Miguel de Cervantes) 1/6

- Pastores de Belén: (Lope de Vega) 1/4

No tomo en consideración Barlaam y Josafat (4); Desengaños de Fortuna (1).

12) 1619: «Ruiz (Damián), librero.» Madrid, en El Marqués de Saltillo, op. cit. pp. 283-284.

- Número de registros: 55

- Número de volúmenes: c.690

- Número de registros de novela: 4

- Número de volúmenes de novela: 48

- Relación de títulos, número de registros y número de ejemplares:

- Galatea: (Miguel de Cervantes) 1/12

- Guerras de Granada, 2a parte: (Ginés Pérez de Hita) 1/24

- Pastores de Belén: (Lope de Vega) 1/6

- Siglo de Oro en las selvas de Erifile: (Bernardo de Valbuena) 1/6

No tomo en consideración Desengaños de Fortuna (6).

13) 1626: Francisco de Robles. Madrid, en Jean-Michel Laspéras, «El fondo de librería de Francisco de Robles, editor de Cervantes», Cuadernos Bibliográficos, 38 (1979), pp. 107-138.

- $\quad$ Número de registros: $269+104$

- Número de volúmenes: «El fondo de librería de Francisco Robles (...) con sus 16240 cuerpos (7122 cuerpos de diversas obras y 9118 pliegos de pragmáticas), valorados en 58126 '50 reales» (Laspéras, p. 132)

- $\quad$ Número de registros de novela: 9

- $\quad$ Número de volúmenes de novela: 589

- Relación de títulos, número de registros y número de ejemplares:

- Galatea: (Miguel de Cervantes) 1/17

- Galateo- Lazarillo castigado: (Lucas Gracián Dantisco) 1/18

- Guerras de Granada: (Ginés Pérez de Hita) 1/28

- Peregrino en su patria: (Lope de Vega) 2/14

- Don Quijote. 1a Parte: (Miguel de Cervantes) 1/142 
- Don Quijote. 2a Parte: (Miguel de Cervantes) 1/366

- Don Quijote. 1a y 2a Parte: (Miguel de Cervantes) 1/3

- Don Quijote. 1a Parte: (Miguel de Cervantes) 1/1

14) 1627: Pedro Osete. Valladolid, en A. Rojo Vega, op.cit. pp.233-240.

- Número de registros: 51 resmas de recetaría más 50 de coplas, (101). Cuerpos más resmas: c. 185

- Número de volúmenes: 624 resmas de recetería más 255 de coplas (879)

- Número de registros de resmas de novela: 5

- Número de ejemplares de resmas de novela: 89

- Relación de títulos, número de registros y número de ejemplares:

- Clamades: ( ) $1 / 10$

- Partinuplés: ( ) 1/28

- Oliveros de Castilla: ( ) 1/5

- Roberto el Diablo: ( ) 1/20

- Tablante de Ricamonte: ( ) 1/26

No tomo en consideración: Historia de Carlomagno (20); Doncella Teodor (9); Conde Dirlos (10); Flores y Blancaflor (18); Caballero Asisio (2).

15) 1629: Miguel Martínez. Madrid, en Trevor J. Dadson, «El fondo de librería de Miguel Martínez», op. cit. pp. 502-510.

- $\quad$ Número de registros: 86 (2 registros de libros varios y diversos y 1 de balas de papel)

- Número de volúmenes: «Las 83 entradas registran un total de 5258 tomos» (Dadson, p. 318)

- $\quad$ Número de registros de novela: 3

- Número de volúmenes de novela: 60

- $\quad$ Relación de títulos, número de registros y número de ejemplares:

- Cigarrales de Toledo: (Tirso de Molina) 1/20

- Español Gerardo: (Gonzalo de Céspedes) 1/20

- Sagaz Estacio: (Alonso J. Salas Barbadillo) 1/20

16) 1634: Gabriel Guasp, Palma de Mallorca, en G. Llompart, La imprenta i llibrería de Gabriel Guasp, Palma de Mallorca, Consellería de Cultura, 1989, pp. 16-30.

- $\quad$ Número de registros: c.502

- Número de volúmenes: c.3933

- $\quad$ Número de registros de novela: 11

- Número de volúmenes de novela: 34

- Relación de títulos, número de registros y número de ejemplares: 
- Carnestolendas de Castilla: (G. Lucas Hidalgo) $1 / 4$

- Diana: (Jorge de Montemayor) 1/3

- Experiencias de amor y fortuna: (Francisco de Quintana) 1/5

- Guerras de Granada: (Ginés Pérez de Hita) 1/2

- Guzmán de Alfarache: (Mateo Alemán) 1/1

- Hija de Celestina: (A.J. Salas Barbadillo) 1/6

- Noches de invierno: (Antonio de Eslava) 2/2

- Partinuplés: ( ) 1/8

- Pastor de Fílida: (Luis Gálvez de Montalvo) 1/2

- Selva de Aventuras: (Jerónimo de Contreras) 1/1

No tomo en consideración: Reniegos de Nochebuena (3), Pastor Fido (6), Carlomagno (5), Teágenes y Cariclea (8), Juegos de Nochebuena (1).

17) 1639: Venta de libros de Pedro Escuer al librero de Daroca Juan Francisco Ramí, en Esperanza Velasco, op. cit. p. 264.

- Número de registros: 3

- Número de libros vendidos: 685

- Número de registros de novela: 1

- Número de volúmenes de novela: 25

- Relación de títulos, número de registros y número de ejemplares: Novelas amorosas y ejemplares: (María de Zayas) 1/25

18) 1648: "Librería de Juan Eguía», en A. Rojo Vega, op.cit. pp. 242-243. Vid. indicación en 1. Introducción.

- Número de registros: 36

- Número de volúmenes: 44

- $\quad$ Número de registros de novela: 2

- $\quad$ Número de volúmenes de novela: 3

- $\quad$ Relación de títulos, número de registros y número de ejemplares: - Carnestolendas de Madrid: (Alonso de Castillo Solórzano) 1/1

- Garduña de Sevilla: (Alonso de Castillo Solórzano) 1/2

19) 1648: Alonso Pérez de Montalbán. Madrid, en Anne Cayuela, Un librero en el Madrid de los Austrias, Madrid, Calambur, 2005, pp. 255-349; 359-365.

- $\quad$ Número de registros: c.1431

- Número de volúmenes: «19820 volúmenes» (Cayuela, p. 137)

- Número de registros de novela: 105

- $\quad$ Número de volúmenes de novela: 1965

- Relación de títulos, número de registros y número de ejemplares: 
- Amor con vista: (Juan Enríquez) 1/1

- Arcadia: (Lope de Vega) 3/21

- Auroras de Diana: (Pedro Castro) 10/313

- Carnestolendas de Madrid: (Alonso Castillo Solórzano) 5/101

- Celestina: (Fernando de Rojas) 1/1

- Cintia de Aranjuez: (Gabriel del Corral) 9/503

- Curial del Parnaso: (Matías de los Reyes) 1/4

- Diablo Cojuelo: (Luis Vélez de Guevara) 7/292

- Español Gerardo: (Gonzalo de Céspedes) 1/1

- Eustorgio y Clorilene: (Enrique Suárez) 13/279

- Experiencias de amor y fortuna: (Francisco Quintana) 5/45

- Florisel de Niquea: (Feliciano de Silva) 1/1

- Galatea: (Miguel de Cervantes) 1/1

- Garduña de Sevilla: (Alonso Castillo Solórzano) 4/177

- Guerras de Granada: (Ginés Pérez de Hita) 5/15

- Guzmán de Alfarache: (Mateo Alemán) 6/34

- Hipólito y Aminta: (Francisco Quintana) 3/8

- Los más fieles amantes: (Diego de Ágreda) 1/1

- Marcos de Obregón: (Vicente Espinel) 2/2

- Mesón del mundo: (Rodrigo Fernández de Ribera) 8/42

- Novela del más desdichado amante: (Jacinto Abad) 1/50

- Novelas ejemplares: (Miguel de Cervantes) 1/1

- Para algunos: (Matías de los Reyes) 4/8

- Pastor de Fílida: (Luis Gálvez de Montalvo) 1/1

- Picara Justina: (Francisco López de Úbeda) 3/3

- Premio de la constancia y pastores de Sierra Bermeja: (Jacinto Espinel) 2/17

- Prodigiosa historia de los dos amantes: (Gabriel del Corral) 1/1

- Siglo de Oro en las selvas de Erifile: (Bernardo Valbuena) 1/1

- Trabajos de Persiles y Sigismunda: (Miguel de Cervantes) 1/1

- Universidad de amor: (Antolínez de Piedralbuena) 3/40

No tomo en consideración: La mojiganga del gusto (A. Sanz del Castillo) (1); Vida del dichoso desdichado (P. Mateo) (1); Historia ejemplar de las dos constantes mujeres (L. Pacheco) (2); Soledad entretenida (J. Barrionuevo) (14); Escarmientos de Jacinto (182); Noches de Navidad (L. Santa Ana) (3); Plaza universal de todas las artes (C. Suárez de Figueroa) (1); Desengaños de Fortuna (Don Gutierre, Marqués de Careaga) (10); Momo (1); Fénix (4); Arcadia (J. Sannazaro) (1) Noches Claras (M. de Farra) (1).

20) 1650 «Librería de Jerónima de Acao» en A. Rojo Vega, op. cit. pp. 243-247. Vid. indicación en 1. Introducción. 
- $\quad$ Número de registros: c. 147

- $\quad$ Número de volúmenes: c. 836

- $\quad$ No aparece novela

\section{NOVELA EN EL CONJUNTO DE FONDO DE LA LIBRERÍA}

En términos absolutos, aunque no se me ocultan los problemas, variables y dificultades del dato, sin contar los inventarios 4,6,7 y 8 , tenemos que de c.79931 volúmenes en total los de novela son c.3694, es decir, un 4,62 \%. De c.4545 registros en total, los de novela son 261, es decir 5,74\%. Ya son suficientemente orientativos estos datos, aunque no les concedamos una exactitud matemática. Pero conviene considerarlo en las distintas librerías para acercarse a la realidad de la proporción de novelas, con respecto al fondo total de la librería.

Por número de registros, téngase presente lo que se dijo al comienzo, tenemos (no tomo en consideración inventarios 4, 6, 7, 8 y los que no tienen novela ) (indico número de inventario y \%):

De 1 a $3 \%$ : $9(2,02 \%) 11$ (2,04\%) $13(2,41 \%) 14(2,70 \%) 16(2,19 \%)$

De 3 a $5 \%: 15(3,61 \%)$

De 5 a $8 \%$ : $2(7,63 \%) 12(7,27 \%) 18(5,55 \%) 19(7,33 \%)$

Más de $8 \%$ : $3(14,28 \%) 5(8,52 \%) 17(33,33 \%)$

Por número de volúmenes:

Menos de $1 \%$ : $9(0,61 \%) 11(0,86 \%) 16(0,86 \%)$

De 1 a $3 \%$ : 15 (1,14\%) 5 (1,29\% contando todo)

De 3 a $7 \%$ : $2(5,24 \%) 5(4,09 \%$ contando sólo libros) $12(6,95 \%) 13$ $(3,62 \%) 17(3,64 \%) 18(6,81 \%)$

Más de $7 \%$ : $3(52,97 \%) 14(10,12 \%) 19(9,91 \%)$

No puede decirse, a la vista de todo esto, que sea importante la presencia de novela en librerías.

Puede afirmarse que, frente a lo que ha retenido la memoria literaria, frente a la imagen construida del pasado, los compradores que se acercaban a las librerías del siglo XVII encontraban una variada oferta de títulos que eran el día a día, pero que no siempre han dejado rastro significativo en la reconstrucción hoy de ese pasado. Es la distancia que va de lo que se vivía en el siglo a lo que el tamiz del tiempo ha seleccionado. Pero es que también en las bibliotecas particulares -como he estudiado ${ }^{5}$ - la presencia de novela es muy limitada,

5. Me ocupo de todo esto en mis estudios en prensa: «Novela en bibliotecas particulares del Siglo de Oro (I): caballerías y géneros afines», Homenaje a J. Caravaggi, Universidad de 
reproduciendo lo que ocurre en las librerías, aunque allí entren otras variables (comunicación oral, ausencias en los inventarios, préstamos, etc.), como analizo en su lugar. No dejaré de decir que en las librerías, además de novela, aparecen otros géneros literarios como teatro, poesía, pero no en proporción significativa ni importante. La literatura, pues, parece que ocupaba un lugar menor en la oferta de las librerías españolas del siglo XVII, y, como he dicho, en las bibliotecas privadas. Pero no entro, aquí y ahora, en los resbaladizos terrenos de la lectura, como explico y razono en mis estudios citados (vid. nota 5). Cabe preguntarse, entonces, por las características y composición del fondo de las librerías.

No he hecho para el caso un estudio comparativo porcentual por materias, pero a la vista de los inventarios utilizados puedo afirmar-algo, por otra parte ya puesto de relieve por varios de los estudiosos citados- que la parte del león se la llevaba el libro religioso (lo mismo que en las bibliotecas particulares), con una gran variedad de géneros: Imitación de Cristo, vidas de santos, devocionarios, catecismos, sermonarios, oratorios, libros de horas, Evangelios, vida de la Magdalena, oraciones, misales, concilios, pasionarios, rosarios, libros de confesión, etc., con presencia repetida de autores importantes como Santa Teresa, fray Luis de León, fray Luis de Granada, etc. Hay que tener muy presente esto para valorar el peso y alcance de la religión -que conocemos por tantos otros datos históricos- en el horizonte mental y en la construcción del imaginario colectivo de los españoles del XVII.

Dato importante es la aparición de los clásicos latinos en casi todas las librerías: Cicerón, Séneca, Ovidio, Plinio, Salustio, Tito Livio, Terencio, Virgilio... etc., sin que falte una habitual presencia de Aristóteles. Nos pone esto ante un peso de la cultura clásica que ha ido diluyéndose después, pero que parece tener una operatividad importante en el siglo.

Los libros de Historia, Derecho, Política, Medicina..., así como los de carácter práctico (lunarios, calendarios, cartillas, gramáticas, retóricas, formularios de cartas, aritmética, etc.) tienen también una presencia destacada en los fondos de las librerías. Pero, como dije, interesado aquí, en particular,

Pavia; «Novela en bibliotecas particulares del Siglo de Oro (II): Pastoril», Homenaje a Sebastián Neumeister, Universidad de Heidelberg; y en «Novela en bibliotecas españolas del Siglo de Oro (1600-1650) (III): Picaresca», Estudos para Maria Idalina Resina, Maria Lucília Pires, Maria Vitalina Leal, ed. I. Almeida, M. I. Rocheta, T. Amado, Lisboa, Universidad, 2007, p. 537-567; «Bibliotecas y novela en el Siglo de Oro», Hispanic Review, 75.2 (Spring, 2007), p. 181-203. Allí tomo en consideración la bibliografía pertinente, analizo los inventarios de bibliotecas y los problemas que plantean. En un estudio sobre librerías y libros a la venta podría ser pertinente, claro, tratar de lectura y bibliotecas y de la ya importante bibliografía sobre ello. No entro en esto aquí, pero remito al lector a mis estudios citados en esta nota. 
por la novela, no puedo presentar ahora datos de proporciones. Pero sí puede afirmarse que el fondo de las librerías era rico, múltiple y variado, con una limitada presencia de la novela -y de la literatura en general- en los términos que hemos visto, pero sobre esto he de volver en próximo estudio.

\section{PERMANENCIA DE TÍTULOS EN EL PERIODO ESTUDIADO}

Todo librero de nuestros días sabe bien la distancia que hay entre el libro fugaz, de corta permanencia en el tiempo, aunque pueda alcanzar grandes ventas en el caso de los best-sellers, y el libro que permanece, el llamado libro de fondo. Me tentaba, con los datos que poseo y sus ya mencionadas limitaciones, aplicar este criterio a la novela en librerías españolas del XVII, pues ese testimonio de permanencia en la memoria, en las expectativas de los compradores puede ser importante para la historia de la literatura del periodo. Aunque, claro, el elevado número de ejemplares de una obra también puede ser interpretado como mala venta.

Con la frialdad de los números -y antes de entrar en los títulos- tenemos que de un total de más de sesenta títulos, sólo cuatro aparecen cinco o seis veces a lo largo del periodo estudiado, dos cuatro veces, tres tres veces, dieciséis dos veces y un grueso resto una vez. Pero, claro, es básico y fundamental saber de qué obras se trata para el balance entre lo esperable y lo no esperable, según el canon de excelencia que ha construido la historia de la literatura. De más a menos el balance de permanencia en el tiempo es el que presento a continuación (doy el título de la obra, el número de inventario de la librería -donde puede verse el título completo- y el año correspondiente, para que pueda valorarse esa permanencia en el tiempo).

Con seis apariciones en el periodo estudiado tenemos dos obras: Arcadia [2, (1601); 5 (1606); 6 (1607); 7 (1608); 9 (1612) 19 (1648)] y Guerras de Granada [2 (1601); 5 (1606); 12 (1619); 13 (1623); 16 (1634) y 19 (1648)]. Con cinco: Guzmán de Alfarache [2 (1601); 5 (1606); 7 (1608); 16 (1634); y 19 (1648)] y Pastor de Fílida [2 (1601); 5 (1606); 9 (1612); 16 (1634) y 19 (1648)]. Con cuatro: Celestina [5 (1606); 6 (1607); 8 (1610) y 19 (1648)] y Quijote: [2 (1601); 5 (1606); 8 (1610); 13 (1623)]. Con tres: Florisel [2 (1601); 5 (1606); 19 (1648)]; Galatea [12 (1619); 13 (1623) y 19 (1648)]; Peregrino en su patria [3 (1605); 5 (1606); 13 (1626)]. El que encontremos en este tramo obras como Arcadia, Guzmán de Alfarache, Celestina, Quijote, Galatea, Peregrino en su patria supone una coincidencia con criterios de valoración de la historia de la literatura, pero también encontramos, con 6 y 5 apariciones obras como Guerras de Granada y Pastor de Fílida, que no 
tienen esa valoración en el canon de excelencia construido por la memoria literaria, lo que muestra la distancia que puede ir de ayer a hoy, es decir, la obligación de la historia de la literatura de atender también a criterios de recepción para reconstruir, con mayor acuidad y pertinencia, el pasado.

Con dos apariciones encontramos abundante número de novelas de distintos géneros (caballería, picaresca, pastoril, cortesana...): Amadís de Grecia [2 (1601); 5 (1606)]; Belianis [2 (1601); 5 (1606)]; Carnestolendas [18 (1648); 19 (1648)]; Diana [4 (1605); 16 (1634)]; Español Gerardo [15 (1629); 19 (1648)]; Experiencias de amor [16 (1634); 19 (1648)]; Galateo y Lazarillo castigado [5 (1606); 13 (1626)]; Garduña [18 (1648); 19 (1648)]; Lazarillo [2 (1601); 5 (1606)]; Novelas ejemplares [11 (1615); 19 (1648)]; Partinuplés [14 (1627); 16 (1635)]; Pastores de Belén [11 (1615); 12 (1619)]; Picara Justina [9 (1612); 19 (1648)]; Primaleón [2 (1601); 5 (1606)]; Selva de aventuras [5 (1606); 16 (1634)]; Siglos de Oro [12 (1619); 19 (1648)]. En este conjunto creo que destaca la reducida presencia de obras importantes como las Novelas ejemplares, de Cervantes; Pastores de Belén, de Lope de Vega; y naturalmente, Lazarillo de Tormes, aunque aquí entran en juego problemas de censura y control en que no puedo detenerme. Excepto en el caso de Partinuplés los libros de caballerías se concentran a principios de siglo.

Por fin hay un nutrido grupo de obras que sólo aparecen una vez en el periodo estudiado: Amadís de Gaula [2 (1601)]; Amor con vista [19 (1648)]; Auroras de Diana [19 (1648)]; Cigarrales [15 (1629)]; Cintia [19 (1648)]; Clamades [14 (1627)]; Clara Diana [2 (1601)]; Cristalián [5 (1606)]; Curial [19 (1648)]; Diablo cojuelo [19 (1648)]; Diana a lo divino [2 (1601)]; Espejo de caballerias [5 (1606)]; Espejo de caballeros [2 (1601)]; Eustorgio [19(1648)]; Febo [5 (1606)]; Galateo español [2 (1601)]; Hipólito [19 (1648)]; Lisuarte [2 (1601)]; Los más fieles [19 (1648)]; Marcos de Obregón [19 (1648)]; Mesón [19 (1648)]; Ninfas de Henares [5 (1606)]; Noches de invierno [16 (1634)]; Novelas amorosas [17 (1639)]; Novela del más desdichado [19 (1648)]; Oliveros [14 (1627)]; Palmerin [5 (1606)]; Para algunos [19 (1648)]; Persiles [19 (1648)]; Pícaros [2 (1601)]; Policisne [5 (1606)]; Prodigiosa historia [19 (1648)]; Reinaldos [5 (1606)]; Roberto [14 (1627)]; Rogel [5 (1606)]; Sagaz Estacio [15 (1629)]; Sergas [2 (1601)]; Tablante [14 (1627)]; Universidad de amor [19 (1648)]. Destaca el que Persiles, en que Cervantes había puesto tanto esfuerzo e ilusión, aparezca una sola vez. También es significativo lo que ocurre con los Cigarrales de Tirso de Molina y El diablo cojuelo de Vélez de Guevara, aunque en este caso hay que tener en cuenta la fecha de la edición, editor y número de ejemplares (vid. Inventario19). Hay una concentración de libros de caballerías a principios de siglo -aunque encontramos algunos en 1627- y una ausencia a lo largo 
del periodo estudiado, coherente con lo que veíamos en el apartado anterior. Por otra parte, nos descubren los datos la presencia de la novela pastoril con obras menos consideradas, la poca abundancia de novela picaresca y la concentración de novela cortesana hacia mediados de siglo, según la evolución del gusto literario.

\section{NÚMERO DE EJEMPLARES DE NOVELAS}

El número de ejemplares de una novela es dato que puede prestarse a distintas interpretaciones, pues tanto puede indicar éxito, en cuanto a expectativas de venta, como lo contrario: ejemplares sin vender. Por otra parte, como se verá, el elevado número de ejemplares en una librería puede deberse a la coincidencia de librero y editor de la obra en la misma persona, a cierto grado de exclusividad, lo que, naturalmente hace cambiar la valoración del dato.

Habría que ponerlo en relación, además, con el número de tirada, para lo que nos faltan datos ciertos y con la fecha de edición, dato éste que no registran los inventarios. Con las salvedades apuntadas me parece significativo que de varias novelas sólo se registre un ejemplar en el periodo estudiado: Amor con vista; Carnestolendas de Madrid; Cristalián; Espejo de caballerías; Espejo de caballeros; Lisuarte; Los más fieles; Ninfas del Henares; Palmerín; Persiles; Premio a la constancia; Prodigiosa historia; Reinaldos; Rogel. Significativamente, la mayor parte son libros de caballerías, aunque aparece novela pastoril y cortesana. De dos a diez, que también es número escaso: Espejo de caballeros (2), Febo (2); Marcos de Obregón (2), Noches de invierno (2); Policisne (2); Sergas (2); Selva (3); Belianis (4); Carnestolendas de Castilla (4); Curial (4); Cristalián (5); Diana, de Montemayor (5); Oliveros (5); Picara Justina (5); Hija de Celestina (6); Clara Diana (7); Novelas ejemplares (7); Siglo de Oro (7); Diana a lo divino (8); Hipólito (8); Para algunos (8); Amadís de Gaula (9); Pastor de Fílida (9); Clamades (10); Pastores de Belén (10). Significativamente, vuelve a ser importante la presencia de libros de caballerías, pero encontramos otros géneros y obras de menor entidad; por ello cabe destacar el reducido número de ejemplares de obras tan importantes como Novelas ejemplares de Cervantes y Pastores de Belén de Lope de Vega.

A partir de aquí el orden por número de ejemplares, de más a menos ahora, es el siguiente: Quijote (643); Cintia (503); Arcadia (374); Auroras (313); Diablo (292); Eustorgio (279); Garduña (179); Florisel (141); Guzmán (136); Carnestolendas (102); Primaleón (82); Guerras (77); Experiencias (50); Novela del más desdichado (50); Mesón (42); Universidad de amor (40); 
Galateo y Lazarillo castigado (36); Galateo (30); Galatea (30); Partinuplés (36); Peregrino (27); Tablante (26); Novelas amorosas (25); Español Gerardo (21); Lazarillo (21); Amadis de Grecia (21); Cigarrales (20); Roberto (20); Sagaz Estacio (20); Celestina (18); Premio de la constancia (17).

El que el Quijote ocupe el primer lugar estaría de acuerdo con la importancia de la obra cervantina, pero hay que tener presente el elevado número de ejemplares (512) en la librería de Francisco Robles (inventario 13), editor de Cervantes. Esto mismo afecta a las siguientes novelas en orden de número de volúmenes: La cinta de Aranjuez (503); Auroras de Diana (313); El diablo cojuelo (292); Eustorgio y Clorilene (279), que sólo aparecen una vez en el periodo y, precisamente, en la librería de su editor, Antonio Pérez de Montalbán ${ }^{6}$. Contando con esto destaca el hecho de que dos obras importantes, como La Arcadia de Lope de Vega, y el Guzmán de Alfarache, de Mateo Alemán, aparezcan con un elevado número de ejemplares y con una repetida presencia a lo largo del periodo, independientemente de que también hiciera ediciones Montalbán (pero algo semejante ocurre con Guerras de Granada, de Pérez de Hita, sin que en este caso coincidan memoria literaria e importancia en el siglo). Se acercaría así el canon construido por la historia de la literatura a la «realidad» de las librerías españolas del siglo XVIII. Pero, de nuevo, encontramos un elevado número de ejemplares de obras menores que sólo aparecen en la librería de Montalbán, su editor: Novela del más desdichado amante (50); Mesón del mundo (42); Universidad de amor (40). Incluso de La Garduña de Sevilla (179)- que encontramos dos veces- aparecen 177 ejemplares en la librería del editor Montalbán. Algo semejante ocurre con Carnestolendas de Madrid: 101 de 102 ejemplares y Experiencias de amor: 45 de 50. Todo esto, a la par que relativiza el valor en sí del número de ejemplares, explica el destacado volumen de obras consideradas hoy de menor importancia. Por ello me parece importante destacar novelas que aparecen más de una vez a lo largo del periodo, con elevado número de ejemplares y no asociada su presencia a razones de edición: Primaleón (182); Guerras de Granada (77); Galateo y Galateo y Lazarillo castigado (66); Galatea (30); Peregrino en su patria (27). También las que aparecen una sola vez con importante número de ejemplares: Florisel (141); Partinuplés (36); Roberto (20); y alguna otra por debajo de estas cantidades. Es de destacar que obras como Lazarillo de Tormes -aunque ya aludí a los problemas de censura y control-Cigarrales de Toledo o Celestina, ésta también con problemas de censura, tengan una presencia reducida en librería.

6. Anne Cayuela, op. cit., p. 70 y ss. 


\section{LA REDUCCIÓN DE LA MEMORIA COLECTIVA}

El estudio de los inventarios nos proporciona una lista de más de sesenta títulos de novelas a la venta en el periodo considerado. Comprobamos una presencia de los distintos géneros narrativos (caballerías, pastoril, picaresca, aventuras, cortesana...) y una evolución de los gustos literarios, como ya dije. Pero lo que quiero subrayar es que esta extensa nómina muestra unas marcadas diferencias entre lo que la memoria literaria ha conservado, el canon de las historias de la literatura, y la realidad de las novelas a la venta en las librerías del Siglo de Oro, sin que coincidieran, excepto en alguna ocasión, valor literario «actual» y presencia en las librerías. La diferencia entre lo que hoy es objeto de erudición y conocimiento especializado, por una parte, y lectura y valor admitido, por otra, no coincide con lo que ocurría en el siglo XVII. Estos problemas surgen cuando tenemos en cuenta la recepción frente a unos supuestos valores literarios atemporales.

Por una parte, estaban presentes en las librerías el Quijote, las Novelas ejemplares, la Arcadia, el Guzmán de Alfarache, el Lazarillo, la Celestina, el Peregrino en su patria, la Galatea, la Pícara Justina, el Persiles, las novelas de Zayas..., aunque con las proporciones vistas, lo que coincidiría con las estimativas actuales. Pero, por otra, encontramos una larga lista de novelas, como Clara Diana, Galateo español, Ninfas del Henares, el Sagaz Estacio, Experiencias de amor, Amor con vista, Auroras de Diana, Eustorgio y Clorilene, Mesón del mundo, etc., que hoy son sólo pasto de erudición, frente a lo que pudo ser realidad viva en el siglo. Es verdad que el problema no afecta sólo a la novela. Ocurre algo semejante en teatro, pues sabemos que no coinciden las estimativas actuales, el elenco de obras llevadas repetidamente a escena en nuestros días, y la realidad diaria de los corrales de comedias y coliseos en el XVII, con sus éxitos, reposiciones y fracasos. Todavía en poesía las distancias pueden ser mucho mayores, y bastaría sólo acudir al conocido estudio de Rodríguez Moñino ${ }^{7}$ (aunque hay una bibliografía sobre el tema en que no entro) para tener constancia de ello. Baste recordar ese mundo de academias, justas, poesía en la calle..., que eran realidad diaria de la vida poética.

Cuando menos, apoya todo esto la obligación del historiador de la literatura de acercarse a la «realidad de verdad» de las obras en su siglo, sin que ello invalide, claro, la licitud de la memoria literaria a la altura de cada momento. Pero no es cosa ya de internarse en este boscaje.

7. Antonio Rodríguez Moñino, Construcción critica y realidad histórica en la poesía de los siglos XVI y XVII, Madrid, Castalia, 1965. 
